\title{
PENERAPAN PEMBELAJARAN TEMATIK SD DI INDONESIA
}

Hilda Karli, M.Pd

\begin{abstract}
ABSTRAK
Model pembelajaran tematik sudah mulai diperbicangkan oleh pakar pendidikan di tahun 1999. Pembelajaran tematik yang merujuk pada KBK dan KTSP sudah diberlakukan sejak tahun 2005 yang lalu. Menurut Fogarty ada 10 macam model tematik tetapi yang dipelajari oleh pakar pendidikan Indonesia hanya 3 model yaitu model pembelajaran tematik jenis jaring laba-laba, model pembelajaran tematik jenis terpadu dan model pembelajaran tematik model keterhubungan.

Pembelajaran tematik sebagai suatu pendekatan belajar mengajar yang melibatkan beberapa mata pelajaran dalam satu tema untuk memberikan pengalaman bermakna bagi siswa. Pengalaman bermakna maksudnya anak memahami konsep - konsep yang telah mereka pelajari itu melalui pengalaman langsung dan menghubungkannya dengan konsep lain yang sudah mereka pahami. Untuk Implementasi Pembelajaran tematik di sekolah dasar ada beberapa komponen yang perlu dibahas dahulu seperti metode, penilaian, media, langkah pembelajaran dan peran guru. Setelah itu akan dibahas langkah penyusunan Pembelajaran tematik serta contoh Matriks Tematik, Silabus dan RPP.
\end{abstract}

\section{Kata Kunci: Pembelajaran Tematik, Sekolah Dasar}

\section{A. Pendahuluan}

Sejak bergulirnya kurikulum berbasis kompetensi (KBK) tahun 2004 untuk kelas 1 dan 2 SD dihimbau oleh dinas Pendidikan Indonesia untuk menerapkan pembelajaran tematik. Belum 2 tahun muncul embrio dari KBK yaitu KTSP, tahun 2006 Kurikulum Tingkat Satuan Pendidikan (KTSP) menghimbau kelas 1 sampai 3 SD untuk menerapkan pembelajaran tematik. Alasan pemerintah untuk menerapkan pembelajaran tematik antara lain:1. pola pikiran anak yang masih holistik artinya usia siswa sekitar 4-10 tahun pola pemikirannya masih satu kesatuan, umumnya mereka menjadi berpikir fragmented karena pola asuh orang dewasa yang memisah-misahkannya; 2. Usia siswa SD masih bersifat operasional kongkrit menurut Jean Piaget bahwa pada usia tersebut masih butuh alat peraga (media) yang kongkrit (nyata) untuk menjelaskan suatu konsep; 3. saat proses belajar untuk mengenal suatu konsep tentu tidak lepas dari kehidupan yang paling dekat dengan lingkungan siswa oleh 
karena melalui payung tema yang menarik perhatian siswa ,sang guru dapat membelajarkan beberapa mata pelajaran seperti: Matematika, IPA, IPS, B.Indonesia, Seni Budaya Keterampilan (SBK), PPKn, Agama dan Olahraga. 4. Pembelajaran tematik sudah diperkenalkan sejak siswa duduk dibangku TK oleh karena sangat sinambung sekali ketika siswa kelas 1 sampai 3 SD bahkan siswa 4-6 SD jika memungkinkan waktu dan konsep-konsep yang akan dikaitkan dalam berbagai mata pelajaran menggunakan pembelajaran tematik tersebut.

Metode dan teknik yang digunakan saat proses pembelajaran dapat menggunakan berbagai cara, intinya siswa masih senang bermain oleh karena itu gunakan ajang permainan untuk membelajarkan sisiwa. Istilah dari Maria Montessori adalah Learning by playing sangat cocok diterapkan di kelas TK dan SD kelas rendah sedangkan kelas tinggi lebih cocok menerapkan istilah dari John Dewey yaitu Learning by doing.

Model pembelajaran tematik sudah mulai diperbicangkan oleh pakar pendidikan di tahun 1999. Pembelajaran tematik yang merujuk pada KBK dan KTSP sudah diberlakukan sejak tahun 2005 yang lalu. Pelatihan tematik dari dinas pendidikan atau pemerhati pendidikan untuk mensosialisasikan tematik dari daerah ke daerah hampir seluruh Indonesia. Beberapa komentar dari berbagai pelatihan tematik di Indonesia yang sudah dilaksanakan yaitu: masih banyak guru yang masih bingung dengan pembelajaran tematik walaupun sudah dilaksanakan dari tahun 2002 tapi masih banyak yang salah persepsi mengenai pembelajaran tematik ini. Ironisnya pemerintah Indoensia khususnya dinas pendidikan meminta guru untuk menerapkan pembelajaran tematik tetapi penilaian akhir terutama dirapor belum terpikirkan lebih detail. Sehingga guru menjadi kebingungan dan banyak yang kembali pada model fragmented. Sayangnya instansi pendidikan yang terkait dalam mensosialisasikan pembelajaran tematik sepertinya hanya tahu sedikit tentang pembelajaran tematik ini. Menurut Fogarty ada 10 macam model tematik tetapi yang dipelajari oleh pakar pendidikan Indonesia hanya 3 model yaitu model pembelajaran tematik jenis jaring laba-laba, model pembelajaran tematik jenis terpadu dan model pembelajaran tematik model keterhubungan. Setiap jenis model pembelajaran tematik ada ciri khusus, kelemahan dan 
kebaikannya. Instansi pendidikan terkait dalam mensosialisasikan model pembelajaran tematik ini bersifat banci tau mix artinya gabungan antara model pembelajaran tematik jenis jaring laba-laba dan terpadu. Instansi tersebut melupakan bagaimana cara penilaian akhirnya.

Bahan masukan bagi pemerhati pendidikan dan instansi pendidikan terkait pada saat mensosialisasikan model tematik jangan terlalu dicekoki atau dijejali dengan materi yang baku seperti silabus yang sudah ada dan harus dilaksanakan. Guru perlu paham bagaimana cara membuat silabus, RPP dan implementasinya untuk pembelajaran tematik. Jadi ketika guru-guru diberikan silabus yang menggunakan pembelajaran tematik dari dinas pendidikan setempat maka guru akan paham bukan hanya sekedar tunduk pada dinas tanpa tahu tujuan dan cara penerapan pembelajaran tematik.. Jenis model pembelajaran tematik sebaiknya diperkenalkan kepada para guru, guru diberi kebebasan untuk memilih jenis model pembelajaran tematik sudah barang tentu guru akan tahu konsekuensi yang perlu diambil ketika mereka memutuskan suatu jenis model tematik temasuk penilaian akhir dan jadwal pelajaran. Guru SD tidak mandiri karena terlalu dimanjakan dengan aturan dari dinas pendidikan se tempat yang harus tunduk pada aturan tanpa mensosialisasikan secara detail pembelajaran tematik. Berbeda dengan guru SMP dan SMA yang lebih mandiri, mereka berani sikap dalam menerapkan sesuatu.

Model pembelajaran tematik sudah disosialisasikan ke berbagai daerah hampir di seluruh Indonesia seperti: Medan, Padang, Pekan baru, Lampung, Palembang, Solo, Cilacap, makasar, Ambon, Surabaya, Kupang. Tujuan pelatihan tematik untuk membantu guru untuk mengurangi kebingungan dalam menerapkan pembelajaran tematik di kelas 1-3 SD. Model pembelajaran tematik dihimbau oleh Dinas Pendidikan agar tahun 2010 sudah dapat dilaksanakan dengan baik di seluruh Indonesia. 


\section{B. Konsep Pembelajaran Tematik di Sekolah Dasar}

\section{Pengertian Pembelajaran Tematik}

Pembelajaran tematik sebagai suatu pendekatan belajar mengajar yang melibatkan beberapa mata pelajaran dalam satu tema untuk memberikan pengalaman bermakna bagi siswa. Pengalaman bermakna maksudnya anak memahami konsep - konsep yang telah mereka pelajari itu melalui pengalaman langsung dan menghubungkannya dengan konsep lain yang sudah mereka pahami (Depdikbud, tim pengembang PGSD,1996).

Pendekatan menurut Depdiknas, 2004 adalah suatu pola umum pembelajaran yang tersusun secara sistematis berdasarkan prinsip-prinsip pendidikan, psikologi, didaktik, dan komunikasi dengan mengintegrasikan struktur (langkah pembelajaran, metode, media, manajemen kelas, evaluasi dan waktu yang diperlukan untuk mencapai tujuan pembelajaran secara efektif dan efesien).

Pembelajaran Tematik ini berorientasi pada kebutuhan perkembangan anak artinya menolak drill sebagai dasar pembentukan pengetahuan dan struktur intelektual anak. Jika dibandingkan dengan pembelajaran konvensional maka pembelajaran Tematik lebih menekankan keterlibatan siswa secara aktif baik kognitif maupun skill dalam proses pembelajarannya. Prinsip "Belajar seraya bermain dan Learning by doing” diterapkan dalam pembelajaran Tematik.

Menurut Fogarty, ada 3 macam pembelajaran Tematik yang diperkenalkan di Indonesia terutama di kalangan mahasiswa S1 - PGSD dari 10 macam yang ditulis olehnya. (i) Pembelajaran Keterhubungan (conneccted) adalah pembelajaran dalam satu mata pelajaran yang menggunakan tema untuk mengkaitkan sub bab /bab yang satu dengan lainnya. Misalnya dalam pelajaran IPA ada bab Makhluk Hidup dan Benda maka untuk mengkaitkannya dibuat tema: "Makhluk hidup dan benda di sekitar kita” 


\section{Jenis Pembelajaran Tematik di Indonesia}

\section{a. Pembelajaran Jaring Laba-Laba (Spider Webbed)}

Pembelajaran Jaring Laba-Laba (Spider Webbed) adalah beberapa mata pelajaran yang dikaitkan dalam satu tema dan setiap mata pelajaran diajarkan seperti biasa menggunakan jadwal pelajaran. Penilaian dalam setiap mata pelajaran masih dilakukan seperti biasa sesuai dengan karakteristik dari setiap mata pelajaran. Satu tema dapat dilakukan selama 2 minggu tergantung dari materi yang dikaitkan. Contohnya untuk mata pelajaran BI, MAt, IPA, IPS dan SBK dengan tema Diri Sendiri .

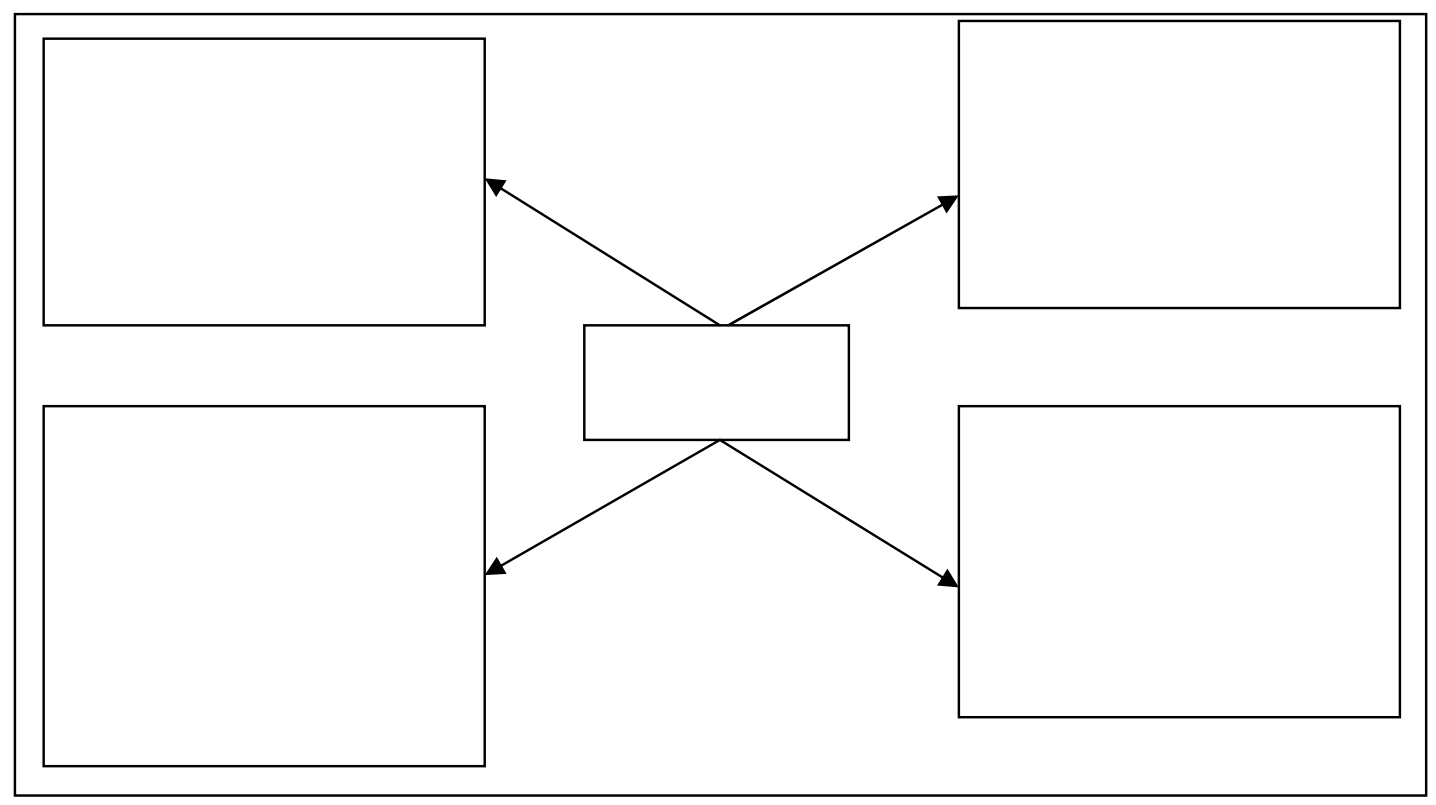




\section{b. Pembelajaran Terpadu (Integrated)}

Pembelajaran Terpadu (Integrated) adalah beberapa mata pelajaran yang dikaitkan dalam satu tema tanpa ada batas satu pelajaran dengan pelajaran lainnya. Satu sub tema dilakukan setiap hari tanpa jadwal pelajaran hanya jam pelajaran yang ditekankan. Penilaian dilakukan secara keterpaduan untuk setiap mata pelajaran dan aspek Kognitif, Afektif dan Psikomotor. Contoh untuk mata pelajaran BI, MAT, IPA, IPS dan SBK dengan tema Diri Sendiri .

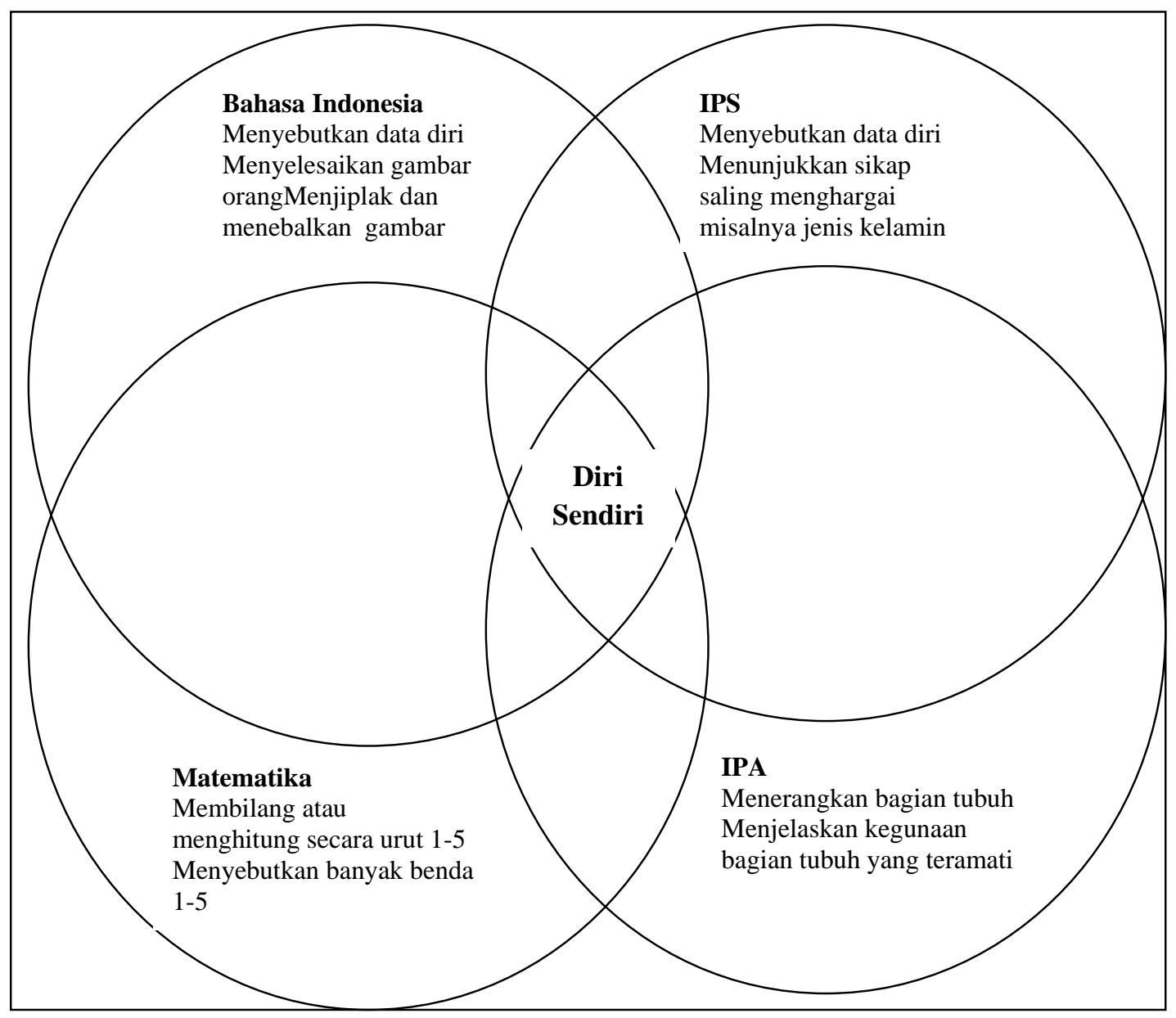

\section{Alasan dan Keguanaan Penggunaan Pendekatan Tematik}

Beberapa alasan mengapa pembelajaran tematik perlu dilaksanakan di kelas 1-3 SD karena: 
a. berpikir masih holistik artinya pada umumnya siswa SD masih berpikir satu kesatuan dan belum bisa terkotak-kotak. Misalnya ketika mereka sedang bermain "kekereta-apian" mereka sibuk mencari penumpang, yang jadi penumpang bayar dengan "uang-uangan”, yang masinis sibuk menjalankan kereta api sambil mengeluarka bunyi “jes...jes...jes”, dst. Bila kita amati maka pelajaran Mat, IPA, IPS, BI, SBK semuanya menjadi satu kesatuan.

b. masih senang bermain artinya siswa TK dan SD masih senang aktif bergerak untuk melancarkan psikomotor kasarnya. Kegiatan yang paling mereka senangi adalah bermain karena bagi mereka bermain adalah ungkapan ekspresi, manipulatif,dan inovasi mereka.

c. rasa ingin tahu yang besar artinya anak usia $4-12$ tahun rasa ingin tahu sangat besar, terlihat dari perilaku mereka ketika mereka berusia balita selalu bertanya mengapa?” , ketika usia mereka di atas balita mulai dengan mengotak-atik mainan bahkan hingga rusak.

d. berpikir operasional kongkrit artinya menurut Jean Piaget , siswa yang berusia 6 - 14 tahun termasuk tingkat berpikir operasional kongkrit. Mereka butuh media/alat peraga yang sebenarnya (real) untuk memahami sesuatu fakta/peristiwa. Mereka belum bisa berpikir abstrak seperti orang dewasa umumnya.

Pembelajaran Tematik selalu berkaitan dengan tema. Kegunaan dalam pembelajaran tematik antara lain:

a. tema gunanya sebagai payung untuk mengkaitkan beberapa mata pelajaran

b. tema harus menarik dan bermakna bagi siswa untuk belajar selanjutnya

c. tema disesuaikan dengan tingkat perkembangan siswa (dari khusus ke umum)

d. tema dipilih sesuai dengan ketersediaan sumber belajar

Contoh tema yang dapat digunakan di kelas seperti: Diri sendiri, keluarga, lingkungan, tempat umum, rumah, pekerjaan, hiburan, pakaian, makanan, transportasi, pariwisata, komunikasi, teknologi, kejadian sehari-hari, negara, pertanian, peristiwa, pendidikan, K3, tumbuhan, binatang, budi pekerti, pengalaman, kesehatan dll. 
Pemilihan tema sebenarnya dibebaskan pada guru disesuaikan dengan kondisi siswa, sekolah dan lingkungan. Guru A dan Guru B mungkin akan berbeda ketika memilih tema untuk mengajarkan "membilang 1 sampai 5", hal ini tidak menjadi masalah yang penting Kompetensi Dasar dari mata pelajaran itu tercapai. Pada akhirnya siswa akan mengerjakan soal dan pemecahan masalah yang umum ditemui di lingkungannya.

\section{Implementasi Pembelajaran Tematik di Sekolah Dasar}

Untuk Implementasi Pembelajaran tematik ada beberapa komponen yang perlu dibahas dahulu seperti metode, penilaian, media, langkah pembelajaran dan peran guru. Setelah itu akan dibahas langkah penyusunan Pembelajaran tematik serta contoh Matriks Tematik, Silabus dan RPP.

Metode yang digunakan dalam pembelajaran Tematik bermacam-macam agar siswa tidak bosan seperti; bermain peran, karya wisata, tanya jawab, eksperimen, bernyanyi, papan buletin, pemberian tugas, pameran, pemecahan masalah, diskusi kelompok, pengamatan, latihan,dll

Penilaian tidak hanya ditekankan pada segi kognitif saja tetapi aspek lannya seperti psikomotor dan afektif pun diperhatikan dalam proses pembelajaran berlangsung. Artinya proses dan produk keduanya diukur saat proses pembelajaran berlangsung dan dilakukan secara terus menerus. Mengukur pengetahuan jauh lebih mudah daripada mengukur keterampilan dan moral siswa karena perlu pengamatan yang terus menerus dari guru untuk melihat tingkat perkembangannya.

\begin{tabular}{|c|l|l|}
\hline No & Alat Penilaian & \multicolumn{1}{c|}{ Bentuk } \\
\hline 1. & $\begin{array}{l}\text { Penugasan } \\
\text { (project) }\end{array}$ & $\begin{array}{l}\text { Bagaimana siswa bekerja dalam kelompok atau } \\
\text { individual untuk menyelesaikan sebuah proyek }\end{array}$ \\
\hline 2. & $\begin{array}{l}\text { Hasil karya } \\
\text { (Product) }\end{array}$ & $\begin{array}{l}\text { Karya seni, laporan, gambar, bagan, tulisan , dan } \\
\text { benda }\end{array}$ \\
\hline 3. & $\begin{array}{l}\text { Unjuk Kerja } \\
\text { (performance) }\end{array}$ & $\begin{array}{l}\text { Penempilan diri dalam kelompok maupun individual } \\
\text { dalam bentuk kedisiplinan, kerjasama, kepemimpinan, } \\
\text { inisiatif, dan penampilan di depan umum }\end{array}$ \\
\hline 4. & $\begin{array}{l}\text { Tes tertulis } \\
\text { paper and } \\
\text { Pencil) }\end{array}$ & $\begin{array}{l}\text { Penilaian yang didasarkan pada hasil ulangan formatif } \\
\text { dan sumatif }\end{array}$ \\
\hline
\end{tabular}




\begin{tabular}{|c|lr|r|}
\hline 5. & $\begin{array}{l}\text { Kumpulan } \\
\text { karya } \\
\text { (protofolio) }\end{array}$ & $\begin{array}{l}\text { Hasil } \\
\text { siswa }\end{array}$ & $\begin{array}{l}\text { Kumpulan karya siswa berupa laporan, gambar, peta, } \\
\text { benda-benda, karya tulis, isian, tabel dll }\end{array}$ \\
\hline
\end{tabular}

Media: lingkungan sekolah, lingkungan kelas, alat peraga yang dibuat oleh guru, majalah, internet, nara sumber (orang tua /guru /keluarga yang diundang) museum, dll

Langkah pembelajaran adalah tahapan saat guru mengajar dikelas menurut Depdiknas, 2004 dan Didi \& Carey, 1976; ada 4 tahap yaitu sebagai berikut.

1. Tahap apersepsi (pembuka) yaitu:kegiatan yang dilakukan diawal pelajaran akan dimulai, misalnya dengan bernyaynyi yang berkaitan dengan tema untuk memancing perasaan senang siswa atau demontrasi suatu kegiatan yang membuat siswa penasaran dan ingin tahu lebih banyak, atau mengajukan pertanyaan yang menantang siswa untuk berpikir lebih lanjut, dll. Fungsi apersepsi untuk memotivasi siswa, mengetahui pengetahuan awal siswa, dan memancing rasa ingin tahu siswa.

2. Tahap penyampaian informasi yatu:kegiatan yang biasa dilakukan oleh guru umumnya , memberikan informasi tentang apa yang akan dipelajari seputar topik atau tema.

3. Tahap partisipasi siswa yaitu:siswa melakukan suatu kegiatan yang melibatkan aspek kognitif, afektif dan psikomotor sebagai suatu rangkaian tugas yang diberikan dalam rangka untuk mencari tahu atau mengeksplorasi tentang suatu topik/tema yang sedang dibahas bisa kelompok atau individu. Bentuk kegiatan ini bisa dilakukan dengan berbagai cara penyampaian nya tergantung dari materi dan mata pelajaran yang akan disampaikan dan yang paling penting tidak membosankan siswa, misalnya pengamatan di halaman sekolah, melakukan percobaan di kelas, permainan, bermain peran, majalh dinding, dll.

4. Tahap penutup (evaluasi dan tindak lanjut) yaitu:kegiatan akhir sari suatu rangkaian KBM di kelas yang sering terlupakan saat di kelas, gunanya untuk memberikan penguatan pada siswa tentang apa yang dibahas/dipelajari pada hari tsb, selain itu untuk mengetahui sejauh mana siswa sudah dapat menerima 
pelajaran, menindak lanjuti materi dengan memberi PR (bertujuan dan tidak membebani siswa) atau menugaskan pengamatan yang berkaitan dengan materi yang sudah dibahas. Cara penyampaian dapat dilakukan secar variatif agar siswa tidak bosan misalnya dengan bernyanyi, kuis, permainan, LKS,dll

Peran guru sebagai fasilitator, mediator dan orang tua bagi siswa kelas 1-3 SD. Artinya guru memberikan kesempatan pada siswa untuk mengekplorasi sendiri dan guru membimbing tahap demi tahap untuk mencari jawabannya sendiri misalnya dengan menyediakan media atau pertanyaan yang bersifat membimbing, dll

Cara menyusun penyusunan pembelajaran Tematik sbb:

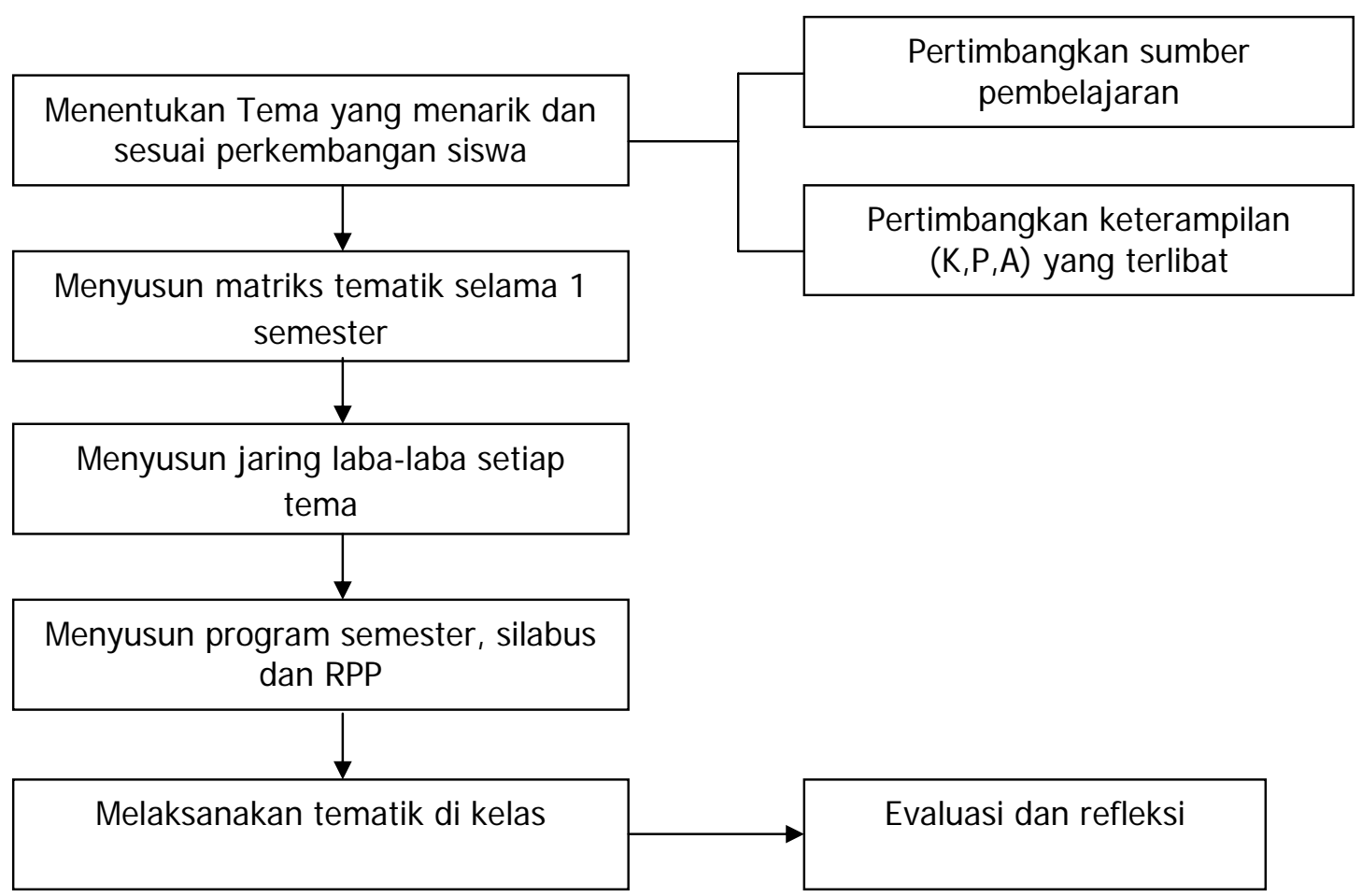

\section{Penutup}

Pembelajaran tematik dapat dilaksanakan di sekolah dasar terutama di kelas 1-3 apabila ada kerjasama yang baik antara instansi yang terkait dengan para guru SD. Pembelajaran tematik ada kelebihan dan kendalanya. Beberapa kelebihan Pembelajaran Tematik adalah:

1. Pengalaman dan kegiatan belajar relevan dengan tingkat perkembangan anak 
2. Hasil belajar akan lebih tahan lama

3. Menimbulkan keterampilan berpikir dan skill

4. Menumbuhkembangkan keterampilan sosial anak seperti; kerjasama, toleransi, komunikasi dan respek terhadap orang lain

Beberapa kendala Pembelajaran Tematik adalah:

1. Perencanaan pembelajaran tematik yang memakan waktu dan tenaga yang lebih banyak mulai dari penyusunan matriks tematik, jaring laba-laba, program semester, silabus dan RPP sekaligus dibuat dalam 1 semester.

2. Tidak berurutan materi yang diajarkan kecuali Matematika dalam 1 semester.

3. Menyiapkan media perlu disesuaikan dengan pemilihan tema.

Beberapa cara mengatasi kendala Pembelajaran Tematik sebagai berikut:

1. Kerja Team Work dari para guru SD tiap jenjang untuk membuat perencanaan hingga pelaksanaan.

2. Para siswa diajak terlibat untuk menyiapkan media sesuai dengan tema 3 hari sebelumnya.

3. Menggunakan bahan ajar tematik untuk membantu guru baik dari persiapan, pelaksanaan bahkan evaluasi.

\section{DAFTAR PUSTAKA}

BSNP. (2006). Model Kurikulum Tingkat Satuan Pendidikan dan Model Silabus Mata Pelajaran SD/MI. Jakarta: BP. Cipta Jaya.

Depdiknas (2000). Naskah Akademik Rancangan KBK. Jakarta: Depdiknas.

Depdiknas (2006). Standar Kompetensi Guru Kelas SD/MI Lulusan S1 PGSD. Jakarta: Direktorat Ketenagaan Ditjen. Pendidikan Tinggi.

Depdiknas (2006). Undang-undang Sistem Pendidikan Nasional. Bandung: Fokus Media.

Depdiknas, (2007). Model Pembelajaran Tematik Kelas Awal SD. Jakarta: Depdiknas.

Fogarty, (1991). How to Integrated The Curricula. Palatine: IRI

Sa’ud, U.S. (2006). Pembelajaran Terpadu. Bandung: UPI Press

\section{BIODATA PENULIS}

Hilda Karli adalah dosen pada Program Studi PGSD UNIKA ATMAJAYA Jakarta. Pendidikan terakhirnya adalah magister pendidikan. 